\title{
Student Preferences and Performance in Online and Face-to-Face Classes Using Myers-Briggs Indicator: A Longitudinal Quasi-Experimental Study
}

\author{
Seta Boghikian-Whitby \& Yehia Mortagy \\ University of La Verne, La Verne, CA, USA
}

\author{
swhitby@laverne.edu; ymortagy@laverne.edu
}

\begin{abstract}
This longitudinal, quasi-experimental study investigated students' cognitive personality type using the Myers-Briggs personality Type Indicator (BMTI) in Internet-based Online and Face-toFace (F2F) modalities. A total of 1154 students enrolled in 28 Online and concurrent 32 F2F sections taught over a period of fourteen years. The study measured whether the sample is similar to the national average percentage frequency of all 16 different personality types; whether specific personality type students preferred a specific modality of instructions and if this preference changed over time; whether learning occurred in both class modalities; and whether specific personality type students learned more from a specific modality. Data was analyzed using regression, t-test, frequency, and Chi-Squared. The study concluded that data used in the study was similar to the national statistics; that no major differences in preference occurred over time; and that learning did occur in all modalities, with more statistically significant learning found in the Online modality versus F2F for Sensing, Thinking, and Perceiving types. Finally, Sensing and Thinking (ST) and Sensing and Perceiving (SP) group types learned significantly more in Online modality versus $\mathrm{F} 2 \mathrm{~F}$.
\end{abstract}

Keywords: Online learning, Distance Education, Face to face (F2F), Myers Briggs (MBTI), Longitudinal, Learning Style.

\section{Introduction}

"Instruction begins when you, the teacher, learn from the learner. Put yourself in his place so that you may understand what he learns and the way he understands it."

- Kierkegaard

Material published as part of this publication, either on-line or in print, is copyrighted by the Informing Science Institute. Permission to make digital or paper copy of part or all of these works for personal or classroom use is granted without fee provided that the copies are not made or distributed for profit or commercial advantage AND that copies 1) bear this notice in full and 2) give the full citation on the first page. It is permissible to abstract these works so long as credit is given. To copy in all other cases or to republish or to post on a server or to redistribute to lists requires specific permission and payment of a fee. Contact Publisher@,InformingScience.org to request redistribution permission.
Students enter a new culture when they enroll in an Internet-based Online or Distance Education course. There is a big paradigm shift between the Face-toFace (F2F) and Online classroom environments (Boghikian-Whitby, 2003). Students who recognize the differences between the two modalities and accordingly adjust their strategies, will find distance education challenging yet ful- 
filling and gratifying. Students who treat both modalities the same will find Online courses more difficult. This can result in poor academic performance and students dropping the course and possibly never taking another online course (Yuan \& Kim, 2014). Current knowledge about student learning styles in Online courses is incomplete.

As decision makers discovered that Online courses can help resolve issues with classroom space, institutions have increasingly begun offering a combination of F2F, Online, and Hybrid course modalities. Some have even started including complete online programs in their strategic plans. However, the question remains whether Online courses produce satisfactory learning outcomes or accommodate differences in student learning styles. Decision makers seem to think that "if we offer courses, students will sign up." However, researchers argue that more needs to be done if we are to understand why students enroll in online courses, and whether personality type is influential in the student selection of course modality (F2F, Online, and Hybrid) (Bolliger \& Erichsen, 2013). In this study, we will only address F2F and Online course modalities.

Colleges wishing to increase their Online course offerings face two major issues. First, in an F2F environment, faculty members usually adjust their teaching styles to accommodate student learning styles based on a reading of body language. This secret ingredient is missing in Online course modalities. As a result, unlike the voluminous literature, spanning decades of research in K-12 and higher learning F2F environments, research into how students fare in Online courses requires further investigation. Second, the taxonomy of students attending college has been changing. Adult nontraditional students, i.e., Baby boomers, single parents, and members of the military, are bringing something different to the table that needs further investigation (DiRamio \& Jarvis, 2015). Educators argue that different personality types have different learning styles which in turn affect student performance (Seiver, Haddad, \& Do, 2014). Therefore, any course that is not carefully planned and delicately orchestrated will only lead to a failure (Boghikian-Whitby, \& Mortagy, 2008). Sadly, Deans only become aware of such failure through official student course evaluations after the course is over.

This paper is written to inform instructors who are interested in developing Online courses to consider students' personality profiles so that they can use the information to improve their course design. In this study, we investigated if our data is comparable with the national average percentage of personality types. Secondly, we investigated if specific personality types of students prefer a specific modality of instructions (F2F versus Online) and if any changes in students' preference have occurred over the last decade. Thirdly, we investigated if learning occurred in both class modalities (F2F versus Online). Finally, we investigated if students with certain personality types learned more from specific modalities (F2F versus Online).

In this quasi-experimental study learning is defined as the cumulative activities of assignments in the duration of the course. The activities include weekly quizzes, homework assignments, midterm exam, weekly case study discussions, research paper, class presentations, and final exam. Learning will be measured by subtracting post-test (i.e., final exam) minus pre-test.

In the following sections, we present the literature review about online learning, personality types, and implication of personality types in education. In the design / methodology / approach section we briefly describe the procedure for the study, and we present the purpose of the study, the research questions and the hypotheses, the study timeline, and the instruments used. In the data analysis section we discuss our findings, results, and practical implications. We conclude the paper by presenting the limitation of the study, by summarizing our findings, and by presenting few key future directions for research. 


\section{Literature Review}

Out of the voluminous literature on student performance and cognitive styles in traditional F2F classroom environments, educators derived theories and devised numerous learning style models to correlate with their theories. Some models are more popular and applicable compared to others based on disciplines. Lakhal, Sévigny, and Frenette (2015) identified and summarized nine such theories with their models as follows:

$\checkmark$ Behavioral theory: Honey and Mumford model (2000)

$\checkmark$ Biological \& Experimental theory: Dunn and Dunn model (Dunn, 1990)

$\checkmark$ Cognitive theory: Gregorc model (Gregorc \& Ward, 1977)

$\checkmark$ Experiential learning theory, David Kolb model (Kolb \& Kolb, 2005)

$\checkmark$ Intelligence theory, Howard Gardner multiple Intelligence model (1999)

$\checkmark$ Meta-learning theory, Flemming VARK model (2001)

$\checkmark$ Neuropsychological theory, Chris Jackson model (2015)

$\checkmark$ Personality theory, Carl Jung (1923) and Myers Brigg Type Indicator (MBTI) model (Myers, McCaulley, Quenk, \& Hammer, 2003)

$\checkmark$ Psychological theory, Felder-Silverman Index of Learning Style model (Felder \& Silverman,1988)

Even though Deborah, Sathiyaseelan, Audithan, and Vijayakumar (2015) used Felder-Silverman Index of Learning Style model in their research, they reported that all of the above mentioned learning style models were equally valid instruments to use for instruction. Similarly Cline, St. John, and Guynes (2015) defined cognitive style as the way individuals think, perceive, and remember information. They compared Myers-Briggs type Indicator (MBTI), Kolb's Learning Style Inventory (LSI), and Human Information Processing Survey (HIPS) because they were the most widely used cognitive style instruments in Information Technology research. They found no statistically significant difference in learning between Myers-Briggs type Indicator (MBTI) and Kolb's Learning Style Inventory (LSI) (Cline et al., 2015). Felder emphasized that educators who strive for excellence must be aware of student learning styles and recommended the integration of diverse strategies to address student needs (Ashraf, Fendler, \& Shrikhand, 2013; Felder \& Brent, 2005). Dorca (2015) attempted to address the student performance issue and measured student's performance using multiple simulations. Similarly, Mikic and Grasso (2002) integrated personality types and teamwork in Teaching Our Youth Technology (TOYtech) course and asked engineering students to design toys for the community. The intention of the course was to encourage teamwork, problem solving, and ethic of social responsibilities in online and face to face environments. Another study investigated female engineering students' type compared to male students and found similar results, concurring that student gender, age, and personality styles play a significant role in academic performance (Village \& Baker, 2013).

To address the problem of student perception of isolation and dropouts in Online environments, Yuan and Kim (2014) recommended creating learning communities to reduce the lack of interaction in Online courses. To make these learning communities successful, they suggested interjecting some fun activities into the course design to create a sense of belonging and social presence. Their experiment compared Myers Briggs Indicator and Pair Programming (PP) in an Online environment. The study reported that "openness played a significant role in differentiating paired students' academic performance. Students reported that PP not only caused an increase in satisfaction and confidence levels, but also brought enjoyment to the tutorial classes and enhanced students' motivation" (Salleh, Mendes, \& Grundy, 2014).

Karn and Cowling (2006) looked at enforcing teamwork in online courses to encourage studentto-student interaction and reported that student's anxiety was elevated and that they did not care for teamwork. Similarly, Lind (1996) conducted a quasi-experiment on New Mexico and Califor- 
nia campuses using case studies where students communicated online and face-to-face. MBTI test was administered at the end of the semester. The study reported that the experiment was successful in creating student-to-student interaction. However, the students faced technical challenges due to the proximity of different campuses.

There were significant studies and comments about the need for student-to-student interaction and student-to-faculty interaction. However, a study found evidence to suggest that in a face-to-face environment levels of anxiety among students feeling social disconnectedness and powerlessness were high, thereby triggering apathy or a lack of caring about being a student (Sashittal, Jassawalla, \& Markulis, 2012)

This study adopted Myers-Briggs type Indicator (MBTI) to examine and identify students' cognitive style since studies have been shown that there are significant effects on students' learning styles (MBTI) and academic performances. It is worth mentioning that all the above problems mentioned in prior research about Online distance learning were delicately addressed in this quasi-experimental study's course design to increase learning, i.e., feeling of belonging and social presence, teamwork, fun activities, student-to-student interaction, and student to faculty interaction.

\section{Online Learning}

Online learning in this study is defined as, "a general term used to cover the broad range of teaching and learning events in which the student is separated (at a distance) from the instructor, or other fellow learners" (Boghikian-Whitby, 2003). Distance education started as correspondence courses. Later the introduction of the Internet made Internet-based distance education appealing.

In Fall 2008, over 4.6 million students in the United States were enrolled in at least one online course; a 17 percent increase over the number reported the previous year (Allen \& Seaman, 2010). In 2009, Doris Bolliger reported 5.6 million students ( $21 \%$ increase) were enrolled in Online courses (Bolliger \& Erichsen, 2013). These numbers are signals that educators need to investigate and identify the ingredients of a successful Online course and to incorporate student learning styles in the course design to increase student learning outcomes.

The question remains, do student enroll in online courses because they are available to them and they do not have any other options to take the course or are students enrolling in online courses because they prefer it compared to F2F courses? Researchers need to investigate student's reasons for enrolling in online courses and examining the data in respect to personality type (Dorca, 2015).

\section{Personality Type}

Seiver et al. (2014) compared students' learning styles using an MBTI assessment after completing an introductory finance class. They used the results to recommend changes in online finance curriculum to accommodate students' learning style.

Jung (1923) first introduced the theory of psychological type. Jung defined personality as a person's combined behavior characteristics and emotions. He further defined personality type as "a type is a characteristic model of a general attitude" (p.612). Jung described the psychological typology:

Its purpose is to provide a critical psychology which will make methodical investigation and presentation of the empirical material possible. First and foremost it is a critical tool for the research worker, who needs definite points of view and guidelines if he is to reduce the chaotic profusion of individual experiences to any kind of order. Secondly, a typology is a great help in understanding the wide 
variations that occur among individuals, and it also furnishes a clue to the fundamental difference in the psychological theories now current. Last but not least, it is essential means for determining the 'personal equation' of the practicing psychologist, who, armed with an exact knowledge of his differentiated and inferior functions, can avoid many serious blunders in dealing with his patients. (p.555)

Myers and Briggs studied Jung's 3 dichotomous types (Extraversion / Introversion, Sensing / iNtuition, and Thinking / Feeling), later they added a fourth type (Judging and Perceiving) and then created the Myers-Briggs Type Indicator (MBTI) instrument. The MBTI instrument consists of four scaled dichotomous types: Extraversion /Introversion, Sensing/ iNtuition, Thinking/Feeling, and Judging/Perceiving. As such, an individual represented by ENTP means that the individual is Extraversion-iNtuition-Thinking-Perceiving. At the end of the test, participants receive numeric values that are called preference scores. These scores show how consistently the participant chooses one preference over the other on each scale. The higher the score the more dominant the preference. Myers emphasized that preference scores do not measure abilities or development.

Lawrence (1993) stated that personality types assist in clarifying behavior and that the MBTI does not evaluate a person's competency. Isabel Briggs Myers indicated that everyone uses all of the preferences at different times. The reported types simply indicate which preference is used most often. Myers also recognized that the MBTI is often misused as researchers tend to look at the dichotomies in isolation from one another, providing an incomplete picture of an individual's preferences (McCaulley, 2000). Therefore, in this study the MBTI instrument was administered in both Online and F2F classes over a period of fourteen years to investigate student performance. Moreover, we not only looked at individual dichotomous types but we looked at combinations of types as recommended by Briggs and McCaulley.

\section{Extraversion / Introversion (E / I)}

This scale deals with where an individual likes to direct his or her attention. Extraverts' energy flows outwards. They focus more on the outer world and draw energy from the people surrounding them. Extraverts are the first ones to raise their hands in the classroom. They are characterized as talkative. On the other hand, Introverts' energy flows inwards. They prefer to focus on the inner world of thoughts, feelings, or impressions. Introverts enjoy their privacy. They tend to speak when they are addressed. They think twice before talking (Bolliger \& Erichsen, 2013).

\section{Sensing / iNtuition (S / N)}

This scale deals with how an individual prefers to take in information. This dichotomy is also known as the perception function. It describes how people receive and process information. Sensors focus on the present reality and on the information brought by their senses. Sensors tend to rely on concrete facts and on the human traditionally recognized five senses: Sight (ophthalmoception), hearing (audioception), taste (gustaoception), smell (olfacception), and touch (tactioception). On the other hand, iNtuitive types rely on experience and relationships. They focus on possibilities and look toward the future. iNtuitive types look for patterns to detect associations (Bolliger \& Erichsen, 2013).

\section{Thinking / Feeling (T / F)}

This scale deals with how an individual prefers to make decisions. This dichotomy is also known as the judgment function because it describes how people evaluate and judge information. Thinkers base their judgments on logic and objective analysis. They are more task oriented and they judge after analyzing all the facts. Thinkers tend to have difficulty expressing emotions. On the other hand, Feelers are more person oriented. They evaluate and judge information by assessing 
personal values and attempt to understand situations. Myers stated that Feelers use empathy and frequently express emotions (Myers et al., 2003).

\section{Judging / Perceiving (J / P)}

This scale deals with how an individual deals with the outer world. Judgers like structure, order, and control. They take a great satisfaction when they complete tasks and find closures. Judgers like a planned and organized approach to life. They tend to want things settled and decided. On the other hand, Perceivers are more spontaneous. They like an adaptable, flexible, and spontaneous approach to life. Perceivers do not like planning because they like to stay open to new opportunities and experiences. They do not mind changes (Bolliger \& Erichsen, 2013).

Each personality variable can be combined with any of the others variables. There are 16 possible combinations $(2 \times 2 \times 2 \times 2)$ :

1. ENFJ: Also known as the Idealist Temperament. Generally Teachers are classified as possessing this type. They are considered as inspiring leaders. They are responsible, warm, and like helping others.

2. ENFP: Also known as the Idealist Temperament. Generally Champions are classified as possessing this type. They are spontaneous and flexible. They are confident, enthusiastic, and make their decisions based on the patterns they see.

3. ENTJ: Also known as the Rational Temperament. Generally Field marshals are classified as possessing this type. They are organized supervisors. They are frank and decisive, they like solving problems and devising policies to eliminate inefficiencies.

4. ENTP: Also known as the Rational Temperament. Generally Inventors are classified as possessing this type. They are outspoken and good at analyzing people. Yet, they are quickly bored and they are interested in new challenges.

5. ESFJ: Also known as the Guardian Temperament. Generally Providers are classified as possessing this type. They are warmhearted, loyal and want to be appreciated. They like harmony more than conflict.

6. ESFP: Also known as the Artisan Temperament. Generally Performers are classified as possessing this type. They are friendly and spontaneous. They have common sense and like collaborating in groups. They do not mind trying new skills.

7. ESTJ: Also known as the Guardian Temperament. Generally Supervisors are classified as possessing this type. They are realistic and decisive. They like to organize projects and lead their team to see their projects through. They are also known as forceful in implementing their plans.

8. ESTP: Also known as the Artisan Temperament. Generally Promoters are classified as possessing this type. They are tolerant but not good with conceptual subjects. They like working with people, energetic participants, and learn best by doing.

9. INFJ: Also known as the Idealist Temperament. Generally Counselors are classified as possessing this type. They are insightful. They are conscientious, committed to their values and determined to implement their vision.

10. INFP: Also known as the Idealist Temperament. Generally Healers are classified as possessing this type. They are loyal and idealistic. They are curious, understand people, and are flexible unless their values are threatened.

11. INTJ: Also known as the Rational or Guardian Temperament. Generally Masterminds are classified as possessing this type. They are independent and skeptical. They have high standards, are perfectionists, and committed to achieve their objectives.

12. INTP: Also known as the Rational Temperament. Generally Architects are classified as possessing this type. They are quiet and skeptical. They are more interested in ideas and solving problems than in social interaction. 
13. ISFJ: Also known as the Guardian Temperament. Generally Protectors are classified as possessing this type. They are quiet and responsible. They are considerate, detail oriented, and concerned about how other feel. They like to keep harmony at home and work.

14. ISFP: Also known as the Artisan Temperament. Generally Composers are classified as possessing this type. They are quiet, kind, and sensitive. They are loyal, do not force their opinions, but committed to their values.

15. ISTJ: Also known as the Guardian Temperament. Generally Inspectors are classified as possessing this type. They are quiet, serious, and dependable. They are detail oriented, very organized, and value loyalty.

16. ISTP: Also known as the Artisan Temperament. Generally Crafters are classified as possessing this type. They are quiet, tolerant, and flexible. They are very organized, analytic, and value efficiency (Keirsey, 1998).

\section{Implication of Personality Types in Education}

Researchers studied and applied Jung's personality types to students' personalities. Educators assessed and changed their pedagogies to accommodate students' personality types to increase learning outcomes.

Deborah et al. (2015) reported that there was no difference in performance between MBTI personality dichotomies in either learning environments (face-to-face versus Online). However, they observed that Sensors/iNtuitive dichotomies were dissatisfied with the amount of interaction in Online environments. Introvert students posted more comments in Online courses compared to Extrovert students. Similarly, Extroverts posted more comments in face-to-face course environment compared to Introvert students. With the Thinker/Feeler dichotomies, Feelers requested more flexibility in online modality compared to Thinkers. Finally, in Judging/Perceiving dichotomies, Judgers posted more comments to improve the course design compared to Perceivers.

Myers first assumed that Extroverts were $75 \%$ of the population. However, later data indicated that it was 50\%. In addition, McCaulley stated that Introverts are more likely to pursue higher education compared to Extraverts (McCaulley, 2000).

Moreover, the literature reflected that Introverts were more open to enrolling in an Online distance learning course (Bolliger \& Erichsen, 2013). Harrington and Loffredo (2010) concurred with the findings. Whereas Extraverts preferred F2F or Hybrid course modalities, researchers found iNtuitive types preferred Online over Blended Hybrid delivery modalities (Daughenbaugh, Daughenbaugh, Surry, \& Islam, 2002).

McCaulley (2000) stated that investigating the 4 individual indicator types alone is not enough. She identified 6 grouping of types that are important for managers and business leaders. The six groups are as follows:

iNtuitive and Feeler (NF): "Enthusiastic and Insightful types." Also known as "Idealist types"

iNtuitive and Perceiver (NP): "The independent, spontaneous types".

iNtuitive and Thinker (NT): "Logical and ingenious types." Also known as "Rationalist types"

Sensor and Feeler (SF): "Sympathetic and Friendly types."

Sensor and Thinker (ST): "Practical and Matter of fact types."

Thinker and Judger (TJ): "The tough minded types."

Myers (1998) concurred that these 6 group types are considered the most important for career satisfaction and she added two more group combinations. Sensor and Judger (SJ): Also known as "Guardian types" and Sensor and Perceiver (SP): Also known as "Artisan types." NF, NT, SJ, 
SP, were categorized as Temperament types (Keirsey, 1998). Myers labeled SF, ST, NF, and NT as Function Pairs (Myers, n.d.). In this study we investigated all 8 combinations.

\section{Design/Methodology/Approach}

\section{Procedure}

This longitudinal quasi-experimental study took place in a private non-profit institution in Southern California. A total of 1154 students were enrolled in a Management of Information Systems in an Online and Face-to-Face (F2F) modality.

The Management of Information Systems class is a required course for all computer science and business majors. In addition, students from different disciplines frequently enrolled in the course because the course satisfied the interdisciplinary general education requirement. All sections were taught by the same professor to control for teaching style, and consistency. The course used Blackboard Inc. as Learning Management System (LMS). Even though multiple sections of the course were taught by different faculty members, their data were excluded from this study.

Adult students could register in either modality with the exception that traditional age students (full time students who are less than 25 years old) who enrolled in the program immediately after high school were allowed to enroll in the online modality only with instructor approval. In order to insure that this process did not negatively influence the results, the national personality profile was compared to the students' personality profile as shown in the first set of hypotheses.

Over the period of 14 years, the faculty used 9 different editions of the textbook. However, students (in both F2F and Online modalities) studied the same course contents, they completed the same homework assignments, and they were allotted the same time for completion of assignments. All students were given the same pre-test, Myers Briggs test, homework, research paper, weekly quizzes, weekly case study facilitation and discussion, and post-test (final exam). The pre-test and post-test were identical. The pre-test was administered at the first week of the semester before the beginning of the course. The post-test was administered at the end of the semester. The pre-test/post-test exam consisted of 100 (multiple choice) questions.

Students were grouped into teams of twos and threes depending on the size of the class. Each team took turns facilitating the case study discussions. All homework assignments were graded using the same grading rubric for both sections. Every student was required to complete a 10 page research paper by the end of the semester. All students filled out a Fact sheet survey at the beginning of the semester (demographic information about the students); they took a midterm evaluation survey in the middle of the semester after taking the midterm exam; and they filled out the final assessment survey at the end of the semester. Finally, all students took the official course evaluation survey that was administered by the university's institutional research department. The analysis of this study was from the following data collection: Pre-test, Post-test, Final grade, Myers-Briggs test (MBTI).

\section{Purpose and Hypotheses}

The purpose of this study is fourfold: First, sample similarity with National Average, investigate whether the sample is similar to the national frequency of all 16 different personality types to generalize our findings. Second, personality type preference, investigate whether specific personality type students preferred a specific modality of instructions and if this preference changed over time. Third, learning, investigate whether learning occurred in both class modalities. Fourth, investigate whether specific personality type students learned more from a specific modality (F2F versus Online). 
There are three sets of hypotheses, the first set deals with changes of percent of student registration over time by personality type. The second investigates if learning has occurred in all modalities. The third deals with differences in the amount of learning that occurs from each class modality by personality type. As such, the following hypotheses are investigated:

Set \# 1: In this set of hypotheses we investigated if there were changes over time in the percent of students of a specific personality type registered in each class modality. Only four hypotheses are needed since each Myers Briggs indicator consists of four types. Each may have one of two values, i.e., ISTJ means the first character type can be either $\mathbf{I}$ or $\mathbf{E}$, second character type can be either an $\mathbf{S}$ or an $\mathbf{N}$, third character type can be either a $\mathbf{T}$ or an $\mathbf{F}$ and fourth character type can be either a $\mathbf{J}$ or a $\mathbf{P}$.

$\mathbf{H}_{1}$ : There is no linear relation between first personality type (Extraversion or Introversion) and time in percent of student registering for each class modality (F2F versus Online).

$\mathbf{H}_{2}$ : There is no linear relation between second personality type (Sensing or iNtuition) and time in percent of student registering for each class modality (F2F versus Online).

$\mathbf{H}_{3}$ : There is no linear relation between third personality type (Thinking or Feeling) and time in percent of student registering for each class modality (F2F versus Online).

$\mathbf{H}_{4}$ : There is no linear relation between fourth personality type (Judging or Perceiving) and time in percent of student registering for each class modality (F2F versus Online).

Set \#2: In this set of hypotheses we investigated if learning occurred in all class modalities.

$\mathbf{H}_{5}$ : There is no significant difference in learning between Post-test and Pre-test for All students.

$\mathbf{H}_{6}$ : There is no significant difference in learning between Post-test and Pre-test for F2F students.

$\mathbf{H}_{7}$ : There is no significant difference in learning between Post-test and Pre-test for Online students.

Set \#3: In this set of hypotheses we investigated the amount (or extent) of learning that has occurred in each class modality. Learning was measured as the difference in the grade between a final exam and identical pre-test. The hypotheses are:

$\mathbf{H}_{\mathbf{8}}$ : There is no difference in the amount of learning between different learning modalities (F2F versus On-line) for personality type Extraversion.

$\mathbf{H}_{9}$ : There is no difference in the amount of learning between different learning modalities (F2F versus On-line) for personality type Introversion.

$\mathbf{H}_{10}$ : There is no difference in the amount of learning between different learning modalities (F2F versus On-line) for personality type Sensing.

$\mathbf{H}_{11}$ : There is no difference in the amount of learning between different learning modalities (F2F versus On-line) for personality type iNtuition.

$\mathbf{H}_{12}$ : There is no difference in the amount of learning between different learning modalities (F2F versus On-line) for personality type Thinking.

$\mathbf{H}_{13}$ : There is no difference in the amount of learning between different learning modalities (F2F versus On-line) for personality type Feeling.

$\mathbf{H}_{14}$ : There is no difference in the amount of learning between different learning modalities (F2F versus On-line) for personality type Judging.

$\mathbf{H}_{15}$ : There is no difference in the amount of learning between different learning modalities (F2F versus On-line) for personality type Perceiving. 
$\mathbf{H}_{16}$ : There is no difference in the amount of learning between different learning modalities (F2F versus On-line) for personality type iNtuition and Feeling (NF).

$\mathbf{H}_{17}$ : There is no difference in the amount of learning between different learning modalities (F2F versus On-line) for personality type iNtuition and Perceiving (NP).

$\mathbf{H}_{\mathbf{1 8}}$ : There is no difference in the amount of learning between different learning modalities (F2F versus On-line) for personality type iNtuition and Thinking (NT).

$\mathbf{H}_{19}$ : There is no difference in the amount of learning between different learning modalities (F2F versus On-line) for personality type Sensing and Feeling (SF).

$\mathbf{H}_{20}$ : There is no difference in the amount of learning between different learning modalities (F2F versus On-line) for personality type. Sensing and Judging (SJ).

$\mathbf{H}_{21}$ : There is no difference in the amount of learning between different learning modalities (F2F versus On-line) for personality type Sensing and Perceiving (SP).

$\mathbf{H}_{22}$ : There is no difference in the amount of learning between different learning modalities (F2F versus On-line) for personality type Sensing and Thinking (ST).

$\mathbf{H}_{23}$ : There is no difference in the amount of learning between different learning modalities (F2F versus On-line) for personality type Thinking and Judging (TJ).

\section{Timeline}

The study started in Fall 2001 through Spring 2015. Sixty different sections were taught over fourteen years (32 F2F sections and 28 Online sections). A total of 1154 subjects participated in the experiment. 598 students were enrolled in F2F sections and 556 students chose to enroll in Online sections.

\section{Instruments}

Data was collected using the following instruments:

1. The MBTI instrument: An online version of the MBTI instrument which consisted of a 72question test. In the first 2 academic years, students took the test using a paper and pencil format, and the results were tabulated manually by the career services director and reported to the instructor. Later, an online version of the instrument, which automatically tabulated scores, was adopted. Students reported their scores to the instructor.

2. A Pre-test exam: A 100 question multiple choice question test was administered during the first week of class for F2F sections (second meeting) and online sections. Students were informed that they were not allowed to read the textbook before taking the pre-test exam.

3. A Fact Sheet survey: An online survey that consisted of 10 general demographic questions was set up on Blackboard and administered during the first week of class.

4. Midterm Evaluation: A 20 question survey was set up on Blackboard and administered after the students took their midterm exam. The instructor tweaked the teaching style and grading rubric based on the results of the midterm evaluation. To stay consistent at all times, any modification made to one Online modality was duplicated to the F2F course.

5. Assessment Survey: An assessment survey to test students' satisfaction with the course was set up on Blackboard and administered during the last week of class.

6. Final Exam (Post-test): The same as the Pre-test exam.

7. Official Course Evaluation: Students were encouraged to take the official course evaluation survey after completing the course.

The Fact Sheet, Midterm Evaluation, Assessment and Official Course Evaluation data were not included in this study. 


\section{Data Analysis}

Quantitative analysis was conducted using SPSS and Excel. Several statistical measures were used to assess and measure the hypotheses.

Sample similarity with National Average: Descriptive statistics using frequency analysis were conducted over all 16 personality types to measure which type signed up for the study's Online courses. The objective was to compare the experiments' data with national frequencies. Later, Chi Square was used to indicate the similarities of the population.

Personality type preference: To analyze Hypotheses 1 through 4, a linear regression was used on every single personality type. The objective was to identify which specific personality type students preferred specific modality (F2F versus Online) of instructions and if the preferences changed over time.

Learning: To analyze if learning has occurred in each class modality, hypotheses 5-7, t-tests were used. Hypothesis 5 was performed using all 1154 students to confirm if learning has occurred. Hypothesis 6 was performed on students attending F2F modality (598 students). Similarly, Hypothesis 7 was performed on students enrolled in Online modality (556 students).

To analyze if the amount of learning, measured as the difference in the grade between final exam (Post-test) and identical Pre-test differed by class modality for each personality type, hypotheses 8 through 23 , t-tests were performed.

\section{Findings/Results}

Sample similarity with National Average: Table 1 presents the percentage of distribution by MBTI of the students enrolled in the Online sections of the study compared to the overall population taken from Myers Briggs Foundation (n.d.). The National percentages are represented in Italic and the bold percentages represent the Online students of this study.

\begin{tabular}{|c|c|c|c|}
\hline \multicolumn{4}{|c|}{$\begin{array}{l}\text { Table 1: } 16 \text { Myers-Briggs Frequencies for Online Students in this Study } \\
\text { Compared to National Data }\end{array}$} \\
\hline $\begin{array}{c}\mathbf{1 .} \\
\text { ENFJ } \\
3.5 \% \\
\mathbf{2 . 5 \%}\end{array}$ & $\begin{array}{c}\mathbf{2 .} \\
\text { ENFP } \\
7.0 \% \\
\mathbf{8 . 1 \%}\end{array}$ & $\begin{array}{c}\text { 3. } \\
\text { ENTJ } \\
3.5 \% \\
\mathbf{1 . 8 \%}\end{array}$ & $\begin{array}{c}4 . \\
\text { ENTP } \\
3.5 \% \\
3.2 \%\end{array}$ \\
\hline $\begin{array}{c}\mathbf{5 .} \\
\text { ESFJ } \\
11.0 \% \\
\underline{\mathbf{1 2 . 3 \%}} \\
\end{array}$ & $\begin{array}{c}\mathbf{6 .} \\
\text { ESFP } \\
6.5 \% \\
\mathbf{8 . 5 \%} \\
\end{array}$ & $\begin{array}{c}7 . \\
\text { ESTJ } \\
10.0 \% \\
\mathbf{8 . 7 \%} \\
\end{array}$ & $\begin{array}{c}\mathbf{8 .} \\
\text { ESTP } \\
4.5 \% \\
\mathbf{4 . 3 \%} \\
\end{array}$ \\
\hline $\begin{array}{c}\mathbf{9 .} \\
\text { INFJ } \\
2.0 \% \\
\mathbf{1 . 4 6 \%} \\
\end{array}$ & $\begin{array}{c}\mathbf{1 0 .} \\
\text { INFP } \\
4.5 \% \\
\mathbf{4 . 4 \%} \\
\end{array}$ & $\begin{array}{c}\mathbf{1 1 .} \\
\text { INTJ } \\
3.0 \% \\
\mathbf{2 . 1 \%} \\
\end{array}$ & $\begin{array}{c}\mathbf{1 2 .} \\
\text { INTP } \\
4.0 \% \\
\mathbf{3 . 3 \%} \\
\end{array}$ \\
\hline $\begin{array}{c}\mathbf{1 3 .} \\
\text { ISFJ } \\
11.5 \% \\
\mathbf{1 3 . 8 \%} \\
\end{array}$ & $\begin{array}{c}\mathbf{1 4 .} \\
\text { ISFP } \\
7 \% \\
\mathbf{8 . 8 \%} \\
\end{array}$ & $\begin{array}{c}\mathbf{1 5 .} \\
\text { ISTJ } \\
12.5 \% \\
\mathbf{1 1 . 6 \%} \\
\end{array}$ & $\begin{array}{c}\mathbf{1 6 .} \\
\text { ISTP } \\
5 \% \\
\mathbf{5 . 4 \%}\end{array}$ \\
\hline
\end{tabular}

The Chi Square indicated that the two populations are similar $(p$-value $=0.923)$. Therefore, the distributions of MBTI for the study were comparable to the national population MBTI distribution average suggesting that the results of the study can be generalized. 
Personality type preference: Table 2 includes the summary of the results of Hypotheses 1 through 4 which investigated, for each personality type, if the percentage of students' registration in Online modality has changed over time. The Appendix presents all the graphs of the hypotheses.

\begin{tabular}{|c|l|r|r|r|l|}
\hline \multicolumn{5}{|c|}{ Table 2: Personality Type \% Registration Over Time } \\
\hline Hypotheses & \multicolumn{1}{|c|}{ Type } & \multicolumn{1}{c|}{ P } & Coefficient & \multicolumn{1}{c|}{ R2 } & \multicolumn{1}{c|}{ Conclusion } \\
\hline $\mathbf{H}_{\mathbf{1}}$ & $\begin{array}{l}\text { Extraversion } \\
\text { or } \\
\text { Introversion }\end{array}$ & 0.184 & 0.007 & 0.09 & No Relation \\
\hline $\mathbf{H}_{\mathbf{2}}$ & $\begin{array}{l}\text { Sensing } \\
\text { or } \\
\text { iNtuition }\end{array}$ & 0.91 & -0.00 & 0.00 & No Relation \\
\hline $\mathbf{H}_{\mathbf{3}}$ & $\begin{array}{l}\text { Thinking } \\
\text { or } \\
\text { Feeling }\end{array}$ & 0.47 & -0.00 & 0.03 & No Relation \\
\hline $\mathbf{H}_{\mathbf{4}}$ & $\begin{array}{l}\text { Judging } \\
\text { or } \\
\text { Perceiving }\end{array}$ & 0.002 & -0.01 & 0.47 & There is a relation \\
\hline
\end{tabular}

The study found Judging, and Perceiving have linear relations. These students changed their preference in a modality over time.

Learning: Table 3 includes the summary of the analysis of hypotheses 5 through 7 . There is significant difference between Post-test and Pre-test for All students: F2F instruction modality and Online modality.

\begin{tabular}{|l|r|r|r|r|l|}
\hline \multicolumn{7}{|c|}{ Table 3: Null Hypothesis Results } \\
\hline \multicolumn{1}{|c|}{ Hypothesis } & \multicolumn{1}{|c|}{ Mean } & \multicolumn{1}{c|}{ df } & t Critical & \multicolumn{1}{|c|}{$\mathbf{P}(\mathbf{T}<=\mathbf{t})$} & Conclusion \\
\hline H $_{5}:$ All subjects & 76.75 & 2062 & 1.96 & 0.0 & Reject \\
\hline H $_{6}:$ F2F & 75.43 & 1053 & 1.96 & $3.76 \mathrm{E}-265$ & Reject \\
\hline H $_{7}:$ Online & 78.33 & 787 & 1.96 & $5 \mathrm{E}-214$ & Reject \\
\hline
\end{tabular}

The study found that there is a statistically significant difference between Post-test and Pre-test, which indicated that students did learn in this class.

Table 4 includes the summary of the analysis of the hypotheses 8 through 23 . These hypotheses investigated if a specific personality type learned more in one class modality compared to the other.

\begin{tabular}{|c|c|c|c|c|c|c|c|c|}
\hline \multicolumn{9}{|c|}{ Table 4: Hypotheses Results } \\
\hline \multirow{2}{*}{$\begin{array}{l}\text { Hy- } \\
\text { pothe- } \\
\text { ses }\end{array}$} & \multirow[t]{2}{*}{$\begin{array}{c}\text { Personality } \\
\text { type }\end{array}$} & \multicolumn{2}{|c|}{$\begin{array}{l}\text { Average Learn- } \\
\text { ing }\end{array}$} & \multicolumn{2}{|c|}{ Sample Size } & \multirow[t]{2}{*}{$\begin{array}{c}\text { t val- } \\
\text { ue }\end{array}$} & \multirow[t]{2}{*}{$\begin{array}{c}P \\
\text { value }\end{array}$} & \multirow[t]{2}{*}{ Conclusion } \\
\hline & & F2F & Online & F2F & Online & & & \\
\hline $\mathbf{H}_{8}$ & Extraversion & 34.1 & 35.95 & 369 & 180 & -1.3 & .19 & Do Not Reject \\
\hline $\mathbf{H}_{9}$ & Introversion & 35.2 & 37.34 & 150 & 127 & -1.06 & .29 & Do Not Reject \\
\hline $\mathbf{H}_{10}$ & Sensing & 33 & 37.45 & 227 & 112 & -2.36 & .02 & Reject \\
\hline
\end{tabular}




\begin{tabular}{|l|l|r|r|r|r|r|r|l|}
\hline $\mathbf{H}_{\mathbf{1 1}}$ & iNtuition & 35.55 & 35.99 & 292 & 195 & -0.31 & .75 & Do Not Reject \\
\hline $\mathbf{H}_{\mathbf{1 2}}$ & Thinking & 32.87 & 36.8 & 275 & 135 & -2.43 & .015 & Reject \\
\hline $\mathbf{H}_{\mathbf{1 3}}$ & Feeling & 36.15 & 36.30 & 244 & 172 & -0.1 & .92 & Do Not Reject \\
\hline $\mathbf{H}_{\mathbf{1 4}}$ & Judging & 35.90 & 36.69 & 436 & 281 & -0.65 & .51 & Do Not Reject \\
\hline $\mathbf{H}_{\mathbf{1 5}}$ & Perceiving & 26.6 & 34.69 & 83 & 26 & -2.42 & .018 & Reject \\
\hline $\mathbf{H}_{\mathbf{1 6}}$ & NF & 36.11 & 36.07 & 151 & 99 & .02 & .98 & Do Not Reject \\
\hline $\mathbf{H}_{\mathbf{1 7}}$ & NP & 29.24 & 33.41 & 33 & 12 & -0.83 & .41 & Do Not Reject \\
\hline $\mathbf{H}_{\mathbf{1 8}}$ & NT & 34.95 & 35.92 & 141 & 96 & -0.47 & .63 & Do Not Reject \\
\hline $\mathbf{H}_{\mathbf{1 9}}$ & SF & 36.21 & 36.63 & 93 & 73 & -0.15 & .88 & Do Not Reject \\
\hline $\mathbf{H}_{\mathbf{2 0}}$ & SJ & 35.24 & 37.68 & 177 & 98 & -1.17 & .24 & Do Not Reject \\
\hline $\mathbf{H}_{\mathbf{2 1}}$ & SP & 24.86 & 35.79 & 50 & 14 & -2.32 & 0.03 & Reject \\
\hline $\mathbf{H}_{\mathbf{2 2}}$ & ST & 30.69 & 38.97 & 134 & 39 & -3.08 & .003 & Reject \\
\hline $\mathbf{H}_{\mathbf{2 3}}$ & TJ & 35.30 & 36.86 & 218 & 128 & -0.91 & .36 & Do Not Reject \\
\hline
\end{tabular}

The results found that there is a statistically significant difference in the amount of learning for types Sensing, Thinking, and Perceiving types as well as the combination grouping ST and SP.

\section{Practical Implications}

By looking at Table 1 we conclude the following:

\section{Sample similarity with National Average:}

1. The distribution of MBTI for this quasi-experimental study was similar to the national population MBTI distribution which allowed us to generalize our results.

2. SFJ personality types, no matter whether they are Extraverts or Introverts, seemed to prefer taking Online courses.

3. ISTJ personality types seemed to prefer enrolling in Online courses.

4. INFJ and ENTJ seemed to have the least preference in enrolling in Online courses.

\section{Personality type preference:}

5. The majority of MBTI types have not changed their registration preference over time. There is no temporal relation or same percentage of students in each type registered in Online classes. Even for those types where a temporal relationship has been identified, i.e., Judging, and Perceiving, the coefficient is too small (maximum is $2 \%$ change).

\section{Learning:}

6. Learning did occur in this class in all personality types $\left(\mathrm{H}_{5}-\mathrm{H}_{7}\right)$.

7. Comparing the personality types to class modality (F2F versus Online), there was no difference in the amount of learning for Extraversion and Introversion types with respect to F2F or Online. This contradicts the literature emphasizing Introverts perform better in Online distance education and Extraverts prefer F2F environment modalities (Deborah et al, 2002).

8. Sensing, Thinking, and Perceiving types learned more or performed better in Online environment compared to F2F modality, with the Sensing showing 13.5\% improvement, Thinking showing 12\% improvement, and Perceiving showing 30\% improvement. 
9. SP and ST group types performed better in Online environment compared to F2F modality, with the SP grouping showing 44\% improvement, and ST grouping showing $27 \%$ improvement. This confirms Myers Brigg's contention that grouping of types are better measured of personality type compared to individual dichotomous types (McCaulley, 2000).

\section{Limitations of the Paper}

This study has three major limitations: First, the research was conducted using the same instructor teaching the same course in one university. On the other hand, the advantage of this limitation is the consistency in running the quasi-experimental study. It is almost impossible for a faculty, especially in technology, to teach the same topic exactly the same way, as teachers constantly improvise, change their teaching styles, and modify their grading rubrics. In this research, the faculty member was able to control numerous variables which would not have been possible if the course was taught by different instructors. Any modifications of the grading rubric were applied equally and at the same time to both modalities.

The second limitation is the age of the students. The majority of the students who were enrolled in Online sections were adult students over 25 years old, whereas students enrolled in F2F sections were a combination of traditional age students and older adult students. Therefore, the effect of student age on performance will be further investigated in a future study.

The third limitation was only one course was used in this study. We wonder if we would see the same results when the experiment is replicated in different disciplines using different courses.

\section{Conclusion}

Even though we had rich literature about various studies, we could not find a study that conducted the Myers-Briggs Indicator test before a course begins. We find that disturbing because faculty members would not have the opportunity to modify their teaching styles to accommodate students enrolled in the class and lose the opportunity identified in Daisley (2011).

The data in this study concluded the following: the data was similar to the national population MBTI distribution statistics which allowed us to generalize our results; that no major differences in registration preference occurred over time; that learning did occur in all modalities and with more statistically significant learning found in the Online modality versus F2F for Sensing, Thinking, and Perceiving types. Furthermore, the combination of $S P$ and $S T$ grouping has performed significantly better in the same modality. Hence, additional research should investigate the reasons for this performance difference.

This study contradicts prior studies that state Introverts are more inclined to be successful in online education (Bolliger \& Erichsen, 2013). It investigated the performance of Introverts in both Online and F2F modalities and found no significant difference in the amount of learning in both modalities.

Another aspect that should be considered for future research is the effects of gender and age of the student in Online environment since Owens (2015) reported that males earn higher salaries compared to females. Moreover, to address one of our limitations, we suggest replicating this study in different disciplines to find out whether similar outcomes would be achieved.

Since one of us taught all these courses, it was gratifying that there was significant difference in learning in all students. 


\section{References}

Allen, I., \& Seaman, J. (2010). Learning on demand: Online education in the United States, 2009. Babson Survey Research Group, 1-29.

Ashraf, R., Fendler, R., \& Shrikhand, M. (2013). Impact of personality types and learning styles on performance of finance majors. Journal of Financial Education, 39(3/4), 47-68.

Boghikian-Whitby, S. (2003). To take or not to take? The future of distance learning: A quasi-experiment comparing of the effectiveness of internet-based distance learning versus face-to-face classroom. Dissertation Abstracts International, 64(02), Section: A, page: 0416

Boghikian-Whitby, S., \& Mortagy, Y. (2008). The effect of student background in E-Learning longitudinal study. Setting Knowledge Free :Issues in Informing Science and Information Technology, $5,107-126$.

Bolliger, D. U., \& Erichsen, E. (2013). Student satisfaction with blended and online courses based on personality type. Canadian Journal of Learning \& Technology, 39(1), 1-23.

Cline, M., St. John, J., \& Guynes, C. S. (2015). Business administration students as surrogates for IT professionals summary of a study. American Journal Of Business Education, 8(1), 7.

Daisley, R. J. (2011). Considering personalitytype in adult learning: Using the Myers-Briggs Type Indicator in instructor preparation at Pricewaterhousecoopers. Performance Improvement, 50(2), 15 24.

Daughenbaugh, R., Daughenbaugh, L., Surry, D., \& Islam, M. (2002). Personality type and online versus in-class course satisfaction: A study of student personlity types showed surprising preferenes for the medium of instruction. EDUCAUSE Quarterly, 25(3), 71-72.

Deborah, L. J., Sathiyaseelan, R., Audithan, S., \& Vijayakumar, P. (2015). Fuzzy-logic based learning style prediction in e-learning. Sadhana, 40(Part 2), 379-394.

DiRamio, D., \& Jarvis, K. (2015). Veterans in higher education: Old friends and new faces. Online: Wiley Online Library. doi:10.1002/aehe.3703

Dorca, F. (2015). Implementation and use of simulated students for test and validation of new adaptive educational systems: A practical insight. International Journal of Artificial Intelligence in Education, $25,319-345$.

Dunn, R. (1990). Understanding the Dunn and Dunn learning style model and the need for individual diagnosis and presciption. Read Write Learn Disability, 6, 223-247.

Felder, R. M., \& Brent, R. (2005). Understanding student differences. Journal of Engineering Education, 57-72.

Felder, R. M., \& Silverman, L. (1988). Learning styles and teaching styles in engineering education. Engineering Education, 78(7), 674-681.

Fleming, N. (2001). Teaching and learning styles: VARK strategies. Fleming Christchurch.

Gardner, H. (1999). Intelligence reframed: Multiple intelligences for the 21st century. New York: Basic Books.

Gregorc, A., \& Ward, H. (1977). A new definition for individual: Implications for learning and teaching. NASSP, 401(6), 20-23.

Harrington, R., \& Loffredo, D. (2010). MBTI personality type and other factors that relate to preference for online versus face-to-face instruction. The Internet and Higher Education, 13, 89-95.

Honey, P., \& Mumford. (2000). The learning styles helper's guide. Maidenead: Peter Honey Publications Ltd.

Jackson, C. $(2015,12$ 1). Manual of the learning styles profiler. Retrieved from Manual of the learning styles profiler http://www.cymeon.com/ 
Jung, C. (1923). Psychological types or the psychology of individuation. New York: Harcourt.

Karn, J., \& Cowling, A. (2006). Using ethnographic methods to carry out human factors research in software engineering. Behavior Research Methods, 38(3), 495-504.

Keirsey, D. (1998). Please unerstand me II: Temperment, Character, Intelligence. Del Mar, CA: Prometheus Nemesis Book Company.

Kolb, A., \& Kolb, D. (2005). Learning styles and learning spaces: Enhancing experiential learning in higher education. Academic Management Lerning Education, 4(2), 193-212.

Lakhal, S., Sévigny, S., \& Frenette, É. (2015). Personality and student performance on evaluation methods used in business administration courses. Educational Assessment, Evaluation and Accountability, 27(2), 171-199. doi:10.1007/s11092-014-9200-7.

Lawrence, G. (1993). People types \& tiger stripes (3rd ed.). Ocala, FL: Center for Applications of Psychological Type.

Lind, M. R. (1996). Student case groups: Electronic groups versus face-to-face groups. Education + Training, 38(6), 10-13.

McCaulley, M. H. (2000). Myers-Briggs Type Indicator A bridge between counseling and consulting. Consulting Psychology Journal: Practice and Research, 52(2), 117-132.

Mikic, B., \& Grasso, D. (2002). Socially-relevant design: The TOYtech Project at Smith College. Journal of Engineering Education, 91(3), 319-326.

Myers, I. B. (n.d.). The 16 MBTI types. The Myers \& Briggs Foundation. Retrieved 12/1/2015, from http://www.myersbriggs.org/my-mbti-personality-type/mbti-basics/the-16-mbti-types.htm

Myers, I. B. (1998). Introduction to type: A guide to understanding your results on the Myers-Briggs Type Indicator (8th ed.). CPP, Inc.

Myers, I. B., McCaulley, M. H., Quenk, N. L., \& Hammer, A. L. (2003). MBTI manual: A guide to the development and use of the Myers-Briggs Type Indicator (3rd ed.). Mountain View, CA: Consulting Psychologists Press..

Myers Briggs Foundation. (n.d.) Myers Briggs statistics. Statistic Brain. Retrieved 5/1/2016 from http://www.statisticbrain.com/myers-briggs-statistics/

Owens, M. (2015). Personality type \& career achievement: Does your type predict how far you'll climb? Truity Psychometrics LLC. San Francisco, CA: Typefinder.

Salleh, N., Mendes, E., \& Grundy, J. (2014). Investigating the effects of personality traits on pair programming in a higher education setting through a family of experiments. Empirical Software Engineering, 19(3), 714-752.

Sashittal, H., Jassawalla, A., \& Markulis, P. (2012). Students' perspective into the apathy and social disconnectedness they feel in undergraduate business classrooms. Decision Sciences Journal of Innovative Education, 10(3), 413-446.

Seiver, D. A., Haddad, K., \& Do, A. (2014). Student learning styles and performance in an introductory finance class. American Journal of Business Education, 7(3), 183.

Village, A., \& Baker, S. (2013). Rejection of Darwinian evolution among churchgoers in England: The effects of psychological type. Journal for the Scientific Study of Religion, 52(3), 557-572.

Yuan, J., \& Kim, C. (2014). Guidelines for facilitating the development of learning communities in online courses. Journal of Computer Assisted Learning, 30, 220-232. 


\section{Appendix}

Extravert type registration in Online course over time.

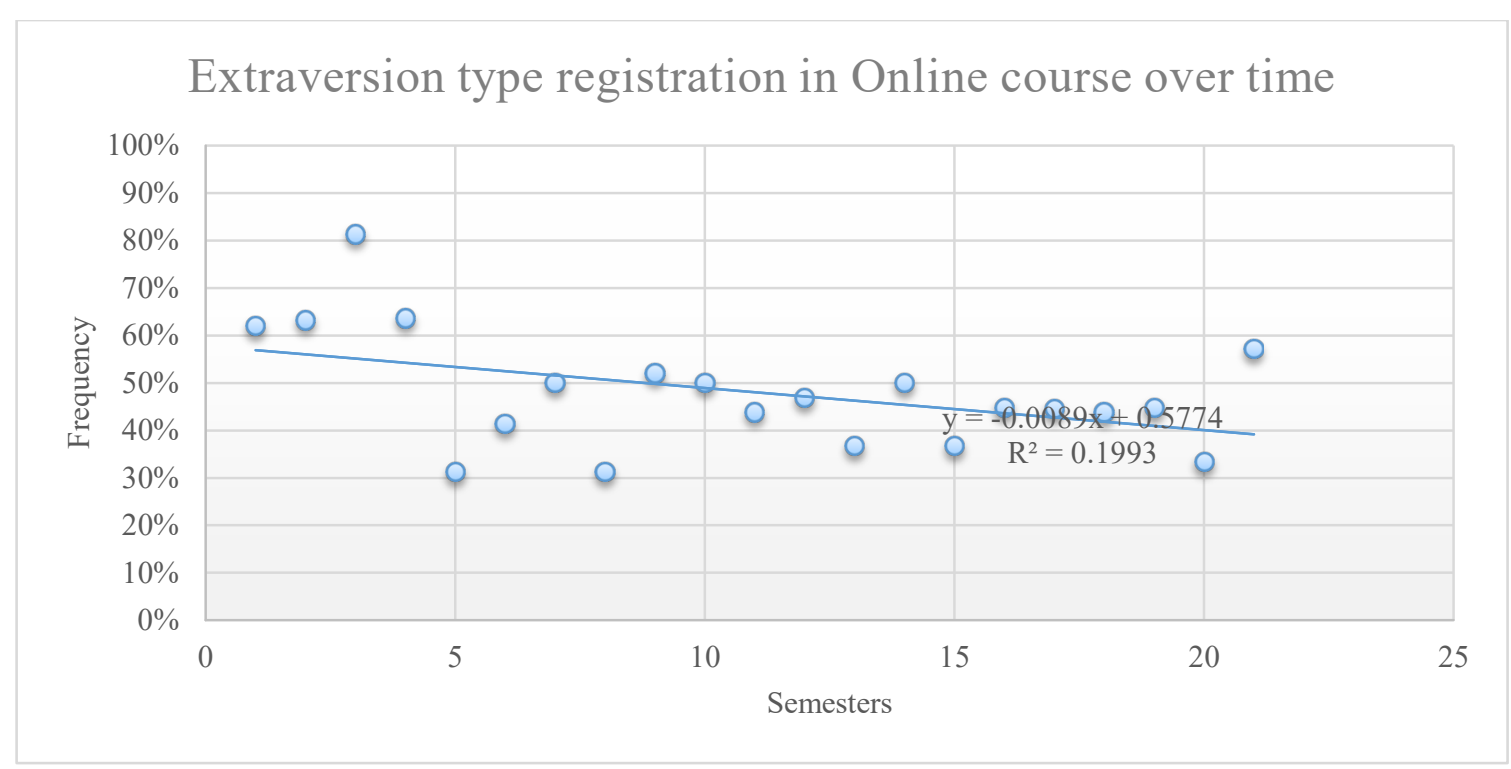

Introvert type registration in Online course over time.

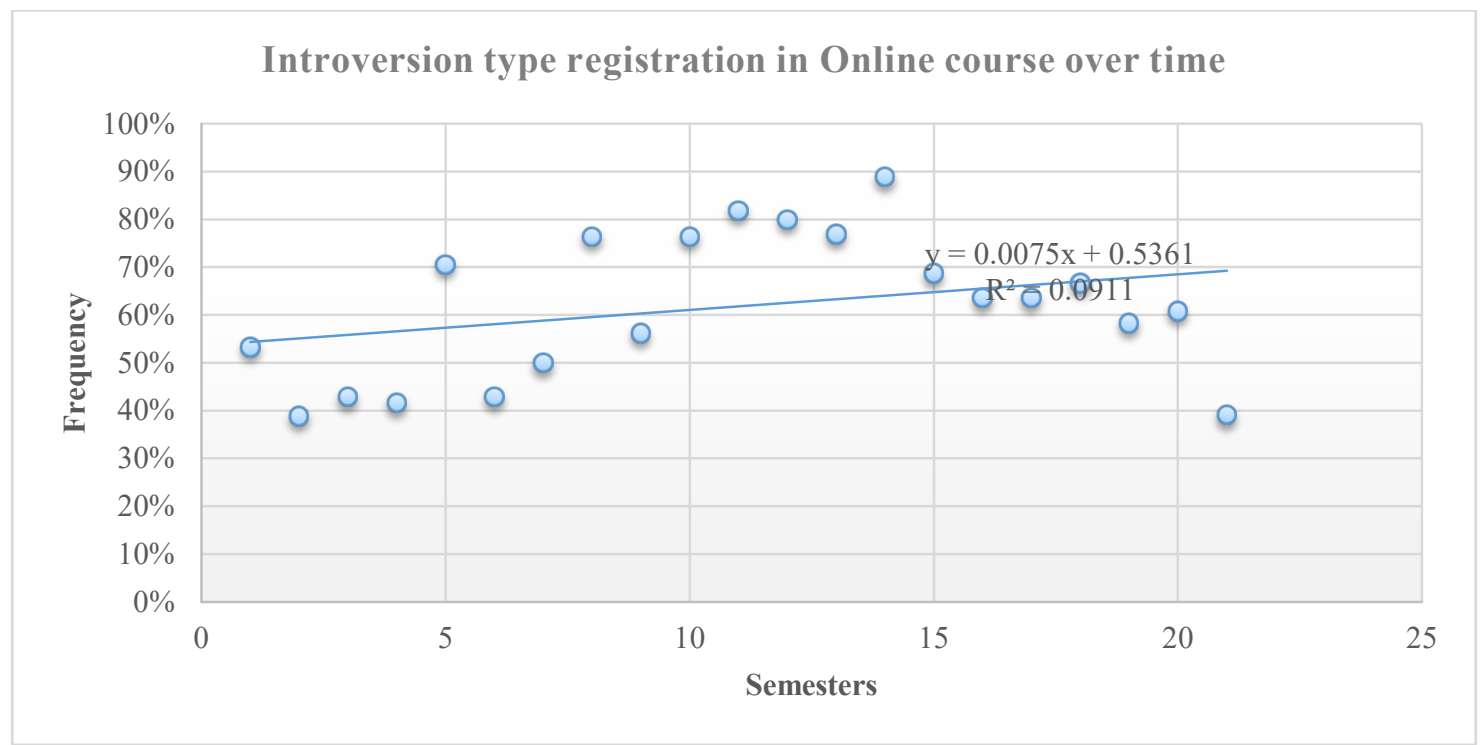


Sensing type registration in Online course over time.

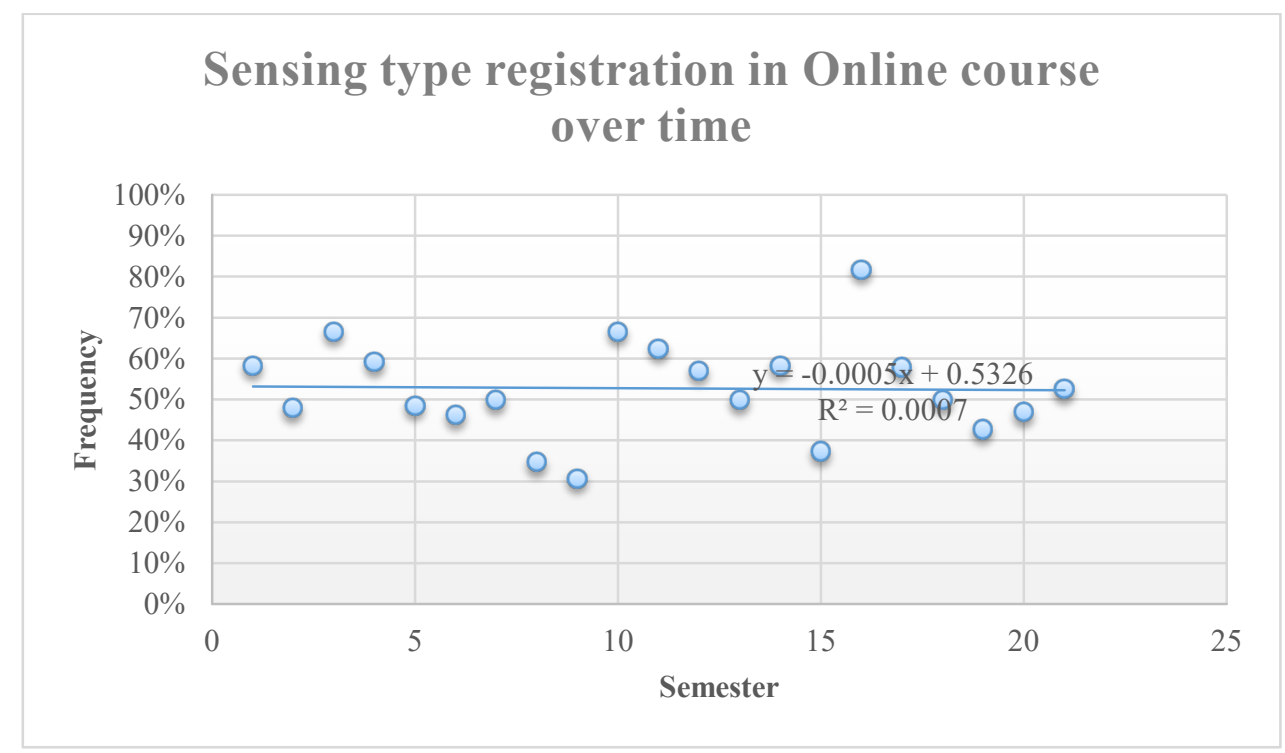

iNtuitive type registration in Online course over time.

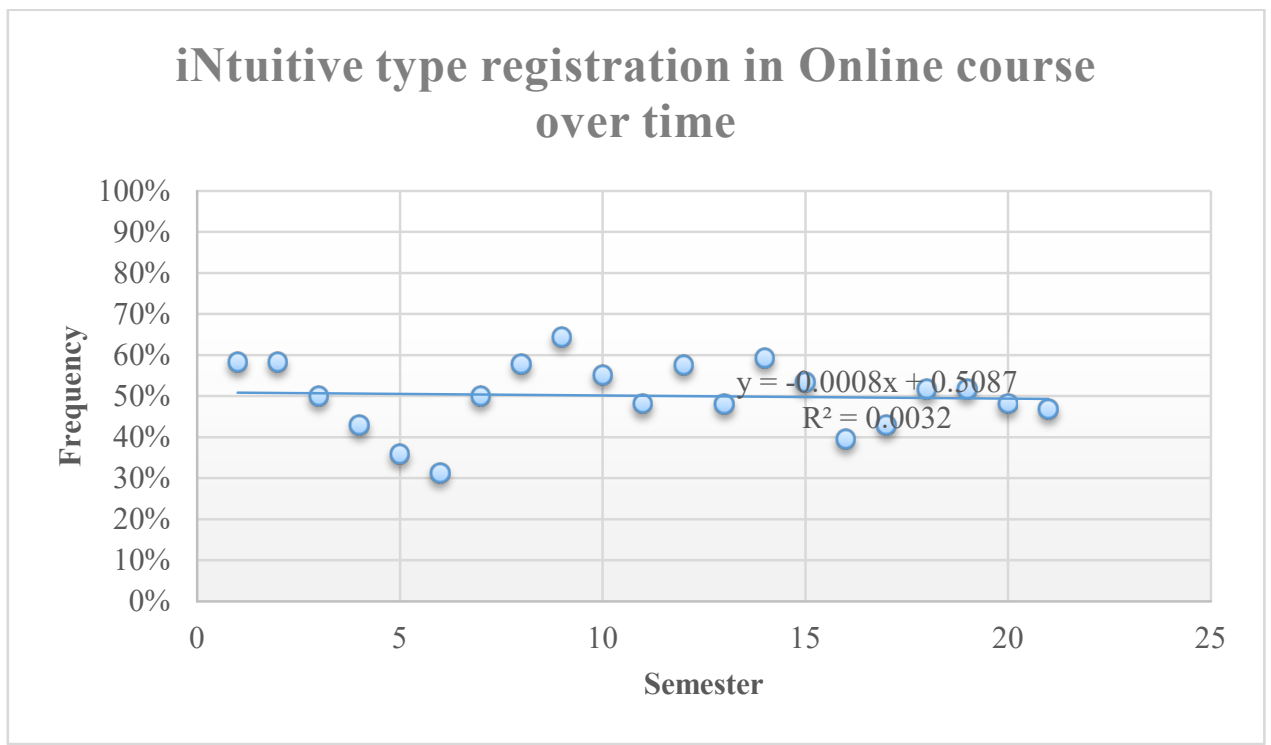


Thinking type registration in Online course over time.

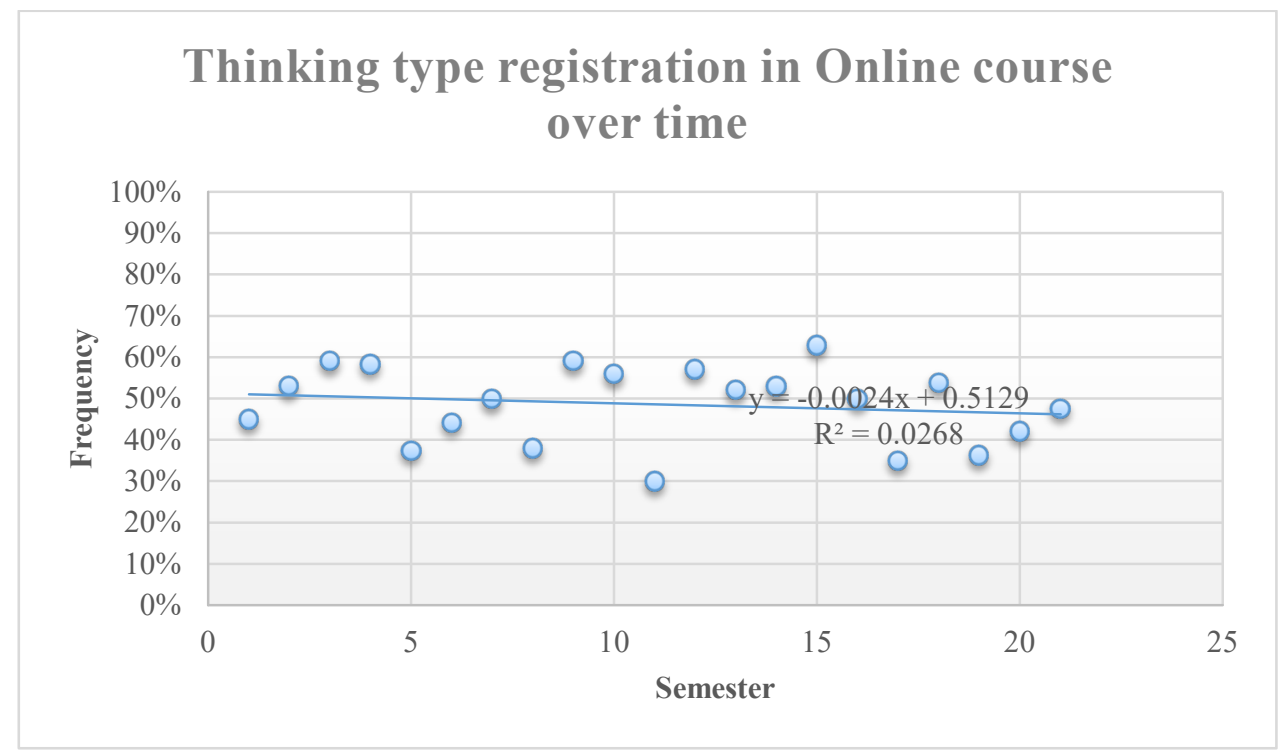

Feeling type registration in Online course over time.

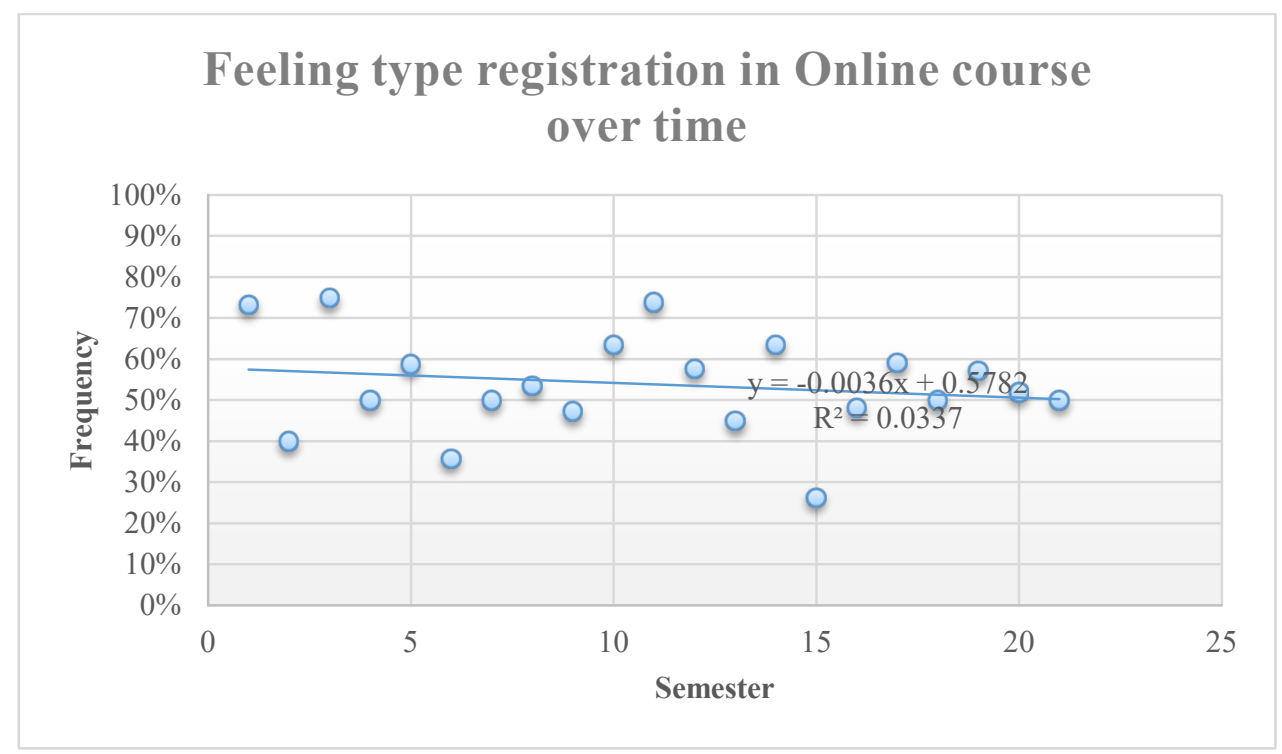


Judging type registration in Online course over time.

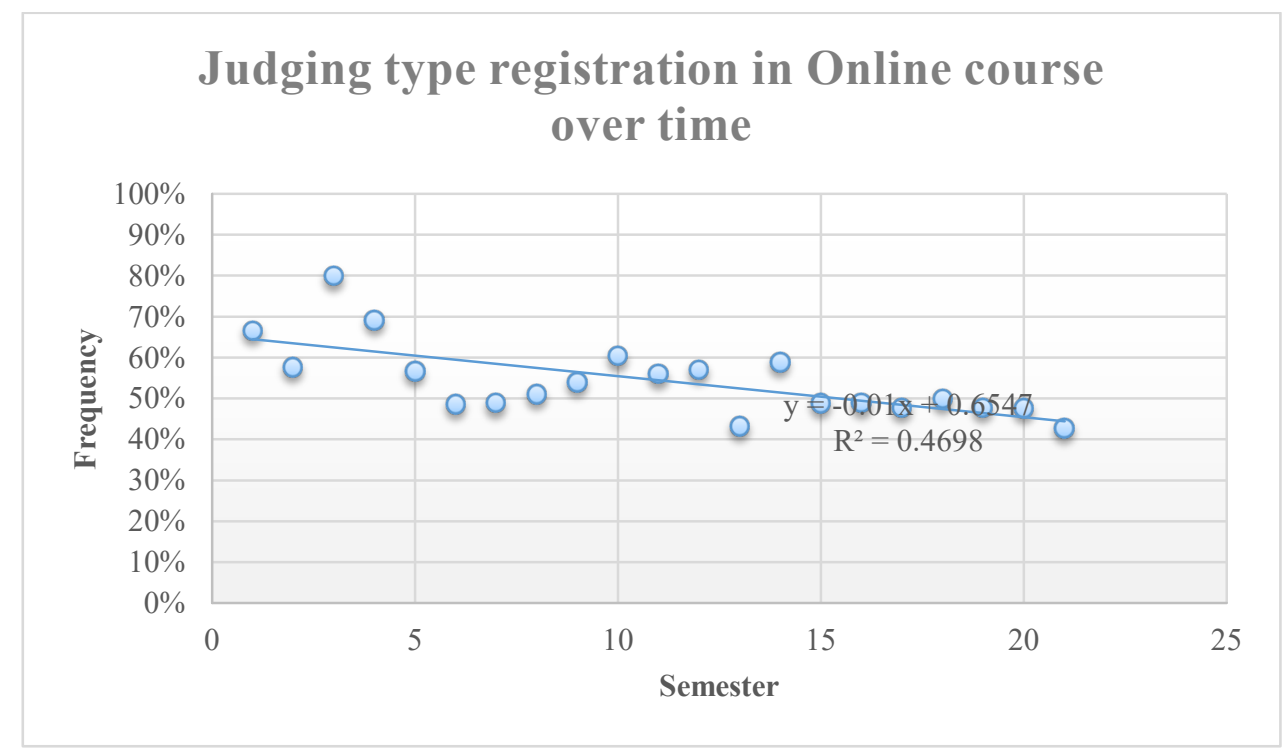

Perceiving type registration in Online course over time.

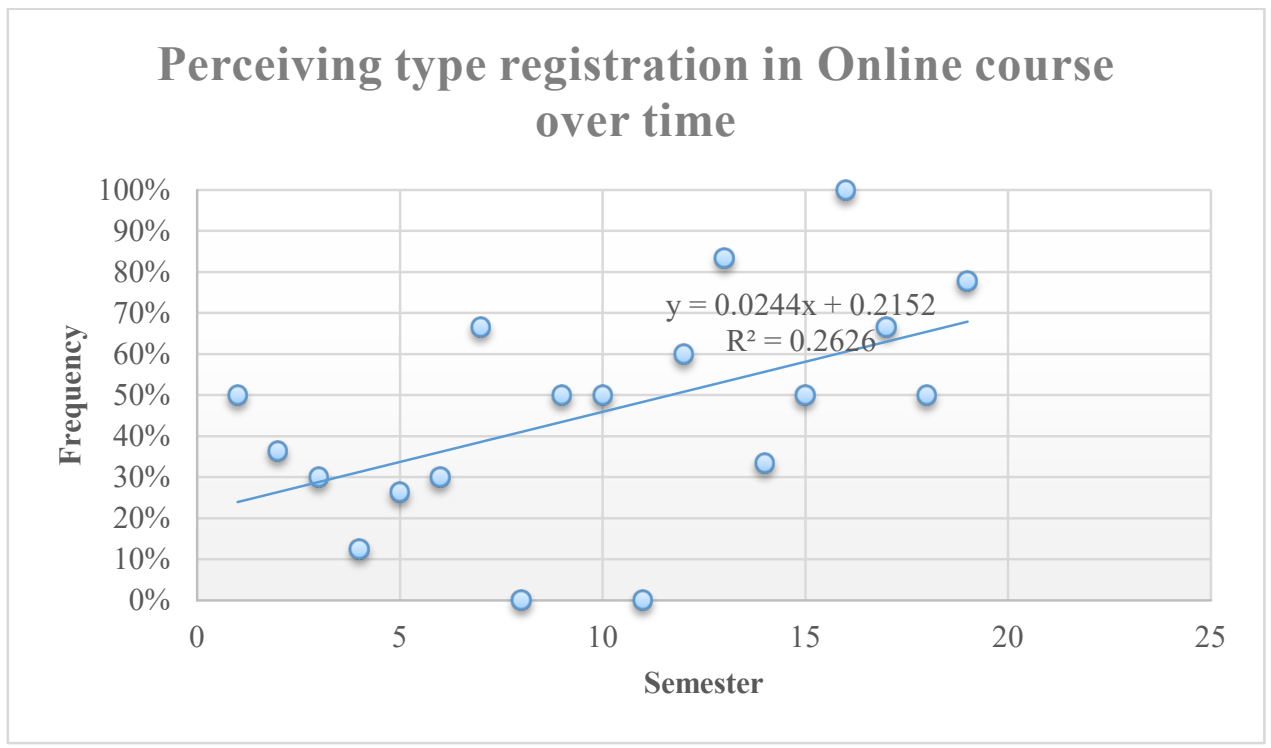




\section{BiographIES}

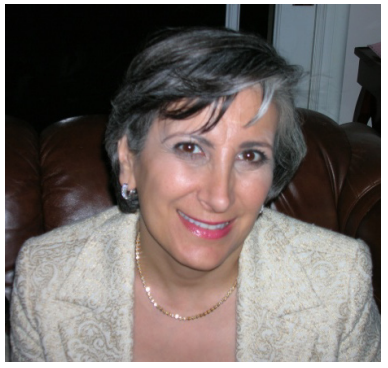

Professor Seta Boghikian-Whitby received her Ed.D. in Organizational Leadership, M.S. in Management of Information Systems, M.E.D. in Computer Education, and B.S. in Computer Science and Computer Engineering.

Professor Boghikian-Whitby is the founder of e-commerce major and Information Science concentration of the Computer Science and Computer Engineering major. She is very active in the faculty governance structure at the University of La Verne - She chaired the Computer Science and Computer Engineering program for 26 years, she is the secretary of the faculty senate, she chaired the Undergraduate Academic Policy (UGAP) and the faculty technology committee, she is an active member of the general education, and faculty personnel committees.

Dr. Seta Boghikian-Whitby, Full Professor College of Arts and Sciences, University of La Verne, La Verne, California 91750 (909) 448-4572 swhitby@1averne.edu

Professor Boghikian-Whitby is active in consultation in information technology area. Her research interests are the adoption of technology in developing countries and e-learning. She has extensive experience in teaching Online distance learning courses. Dr. Boghikian-Whitby is a sought after speaker and a beloved teacher for 32 years.

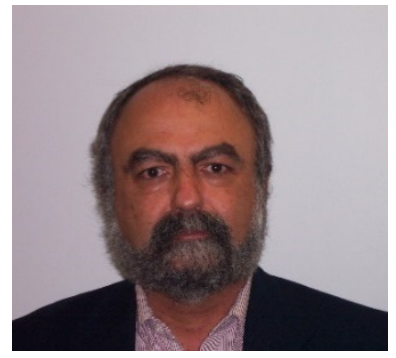

Dr. Yehia K. Mortagy is a professor of information technology and decision sciences at the College of Business and Public Management, University of La Verne, La Verne California. Prior to the University of La Verne, Dr. Mortagy taught at Cal. Poly. Pomona - College of Business and Collins School of Hotel and Restaurant Management -, Naval Postgraduate School in Monterey California. Preceding his academic career, Yehia worked for Bechtel Corporation.

Yehia received his Ph.D. from the Claremont Graduate School, Claremont California, MBA from UCLA and B.Sc. in Aeronautical engineering from the College of Engineering, Cairo University. He has published several articles, book chapters and conference presentations including the chapter on Strategic Information Systems in the Information Systems Encyclopedia. His current research interests include online education and supporting human decision making using information technology.

Dr. Yehia K. Mortagy 'Ben', Professor of Decision and Information Sciences; College of Business and Public Management, University of La Verne, La Verne, California 